\title{
Development of Parametric CAD Model and Structural Analysis of the Car Jack
}

\author{
Nedim Pervan ${ }^{1 *}$, Adis J. Muminović ${ }^{1}$, Adil Muminović ${ }^{1}$, Muamer Delić ${ }^{1}$ \\ 1 University of Sarajevo, Mechanical Engineering Faculty Sarajevo, Vilsonovo šetalište br. 9, Sarajevo, Bosnia \\ and Herzegovina \\ * Corresponding author's e-mail: pervan@mef.unsa.ba
}

\begin{abstract}
The purpose of a car jack is lifting the car and maintaining it at a certain height during different repairs. This paper focuses on the design of car jack, which belongs to the basic equipment of cars. Cars jacks are used mainly for changing tires and small repairs of a car. The aim of this paper was to create a parametric CAD model of a car jack and carry out numerical structural analysis of the car jack using the created parametric CAD model. The development of the parametric CAD model and structural analysis was performed using the CATIA V5 system. This paper describes the modern way of creating more complex mechanisms, which support quick modification of its parameters, and thus the entire design. The whole model of the car jack was parametrized. The stresses obtained by finite element method (FEM) analysis were confirmed with the analytical calculation in characteristic parts of the design, with some exceptions. At the end of the paper, an analysis of the obtained results was performed, on the basis of which specified conclusions were made.
\end{abstract}

Keywords: car jack, parametric model, theoretical analysis, structural analysis

\section{INTRODUCTION}

A mechanical jack is a device which lifts heavy equipment and vehicles so that maintenance can be carried out underneath. The most common reason for using a car jacks is a change of tire, but it can also be used for various other repairs [1]. Currently, there are a lot of different car jacks designs available at the market. They can be divided into two main groups: mechanicalbased (thread spindle) and hydraulic-based. The most important characteristics of every car jack are lift height, load capacity, and static stability during lifting. Stability is especially important for safe lifting. During the design process, for better stability, it is important to seek advice from the people with experience and from technical staff. Stability is mostly defined by the shape and design of the car jack.
Depending on the type of the vehicle and personal requirements from the vehicle owner, there are a lot of different criteria for choosing the right car jack. Basically, every type of car jack is good enough for tire changing. Among the car jacks, there is a lot of differences in the working principles, mode of use, lifting height, load capacity and price. The goal of this paper was to create a parametric CAD model of a car jack. Then, this parametric CAD model was used for numerical

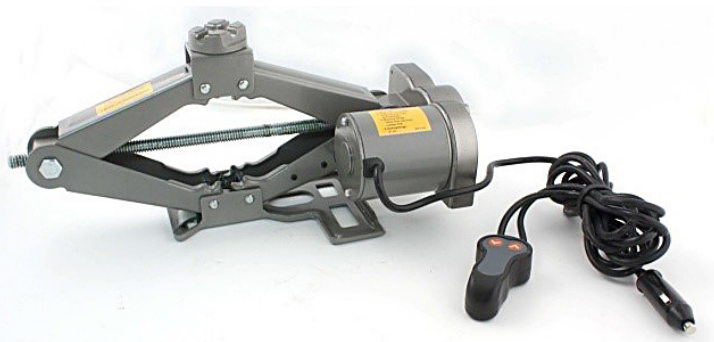

Figure 1. "Scissor" car jack with electrical drive 
structural analysis using finite element method (FEM). For this research, the most common car jack variant was chosen (Figure 1).

A lot of different studies regarding thread spindle car jacks have been perfomed. As a result, numerous patents were filed $[2,5,10,17,20]$.

\section{DEVELOPMENT OF CAR JACK PARAMETRIC 3D MODEL}

The goal of developing a car jack parametric $3 \mathrm{D}$ model is to obtain a functional $3 \mathrm{D}$ model which can be changed easily by editing some of the parameters. In the case of a car jack, it is important to easily change position and shape of the car jack to simulate lifting of a car. This is possible only if the model is fully parametric.

The term parametric design associated with parametric systems is defined as "a process of designing with parametric models in a virtual surrounding where geometrical and parameter variation are natural" $[18,19]$.

Except parameters, for this type of 3D modeling and numerical analysis, it is important to use links to link all individual parts in functional assembly. Using links enables to automatically update all changes on individual parts in all assemblies where that part is copied. In order to enable copying of individual parts, it is necessary to make them public. Before publishing parts, a designer must check the names of all parts, because two or more parts cannot have the same name. Links are especially important to show threads in real form.

The control part is main part of parametric controlled assembly model. Inside this part, there is all information about the assembly, information like coordinate systems, parameters, sketches, planes, etc. Except basic parameters (lift height, length of beams, etc.) this control part has all parameters for all other parts of assembly.

During the numerical structural analysis of the car jack, special focus needs to be placed on the thread spindle and thread nut. Threads need to be modeled as closely to the real one as possible. Modeling of threads is not a problem; however, establishing real connection between thread spindle and thread nut constitutes an issue. This connection can not be established using standard constrains, links needs to be used. Standard constrains can not enable to move thread nut along the thread spindle.

Figure 2 shows a model of thread nut and thread spindle connection. It can be noticed that there is not any material penetration between thread nut and thread spindle. This will stay the same for any position of car jack.

\section{THEORETICAL ANALYSIS OF CAR JACK}

The design of the selected car jack (Figure 1) can be replaced with beam elements connected in joints (Figure 3). Joints A and B are used for fix connection with the ground. This design is statically undefined case, but because the car jack is symmetric, all forces can be calculated analytically.

Because of a symmetric design, (left side is loaded same as right size) forces can be calculated:

$$
X_{A}=X_{B} ; Y_{A}=Y_{B}
$$

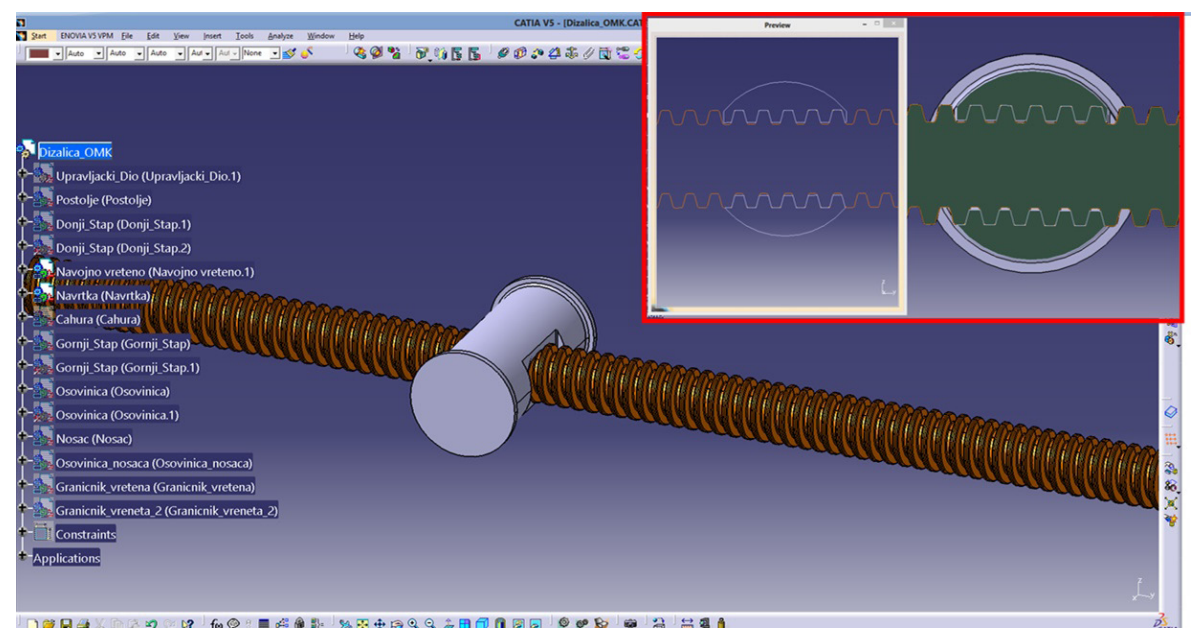

Figure 2. Model of connection of thread nut and thread spindle 


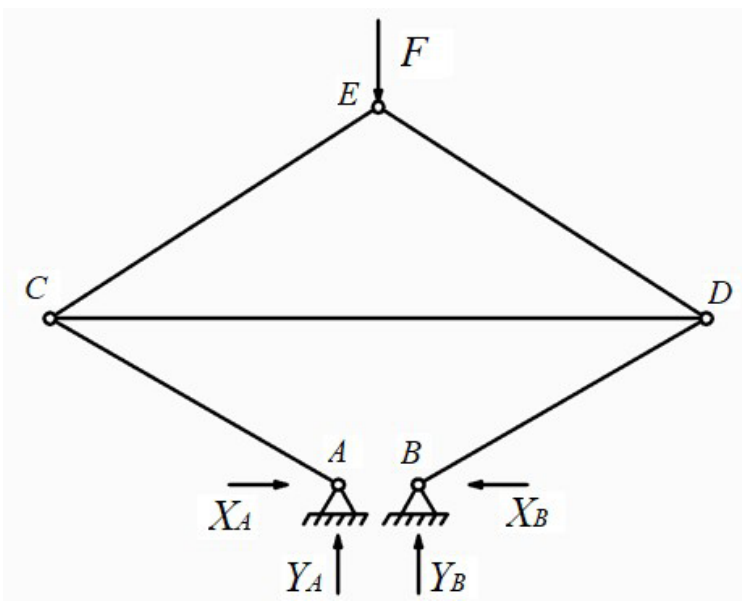

Figure 3. Design of car jack replaced with beams elements and joints.

From static laws for points $E, A$ and $C$, the forces in beams and thread spindle can be calculated:

$$
\begin{gathered}
S_{1}=\frac{F}{2 \sin \beta}=\frac{m g}{\sin \beta} \\
S_{2}=\frac{Y_{A}}{\sin \alpha} \\
F_{V}=S_{2} \cos \alpha+S_{1} \cos \beta
\end{gathered}
$$

where: $F$ - force which represents full load on car jack,

$m=900 \mathrm{~kg}-$ load of the car jack in form of mass,

$g=9.81 \mathrm{~m} / \mathrm{s}^{2}-$ gravitational acceleration .

a)

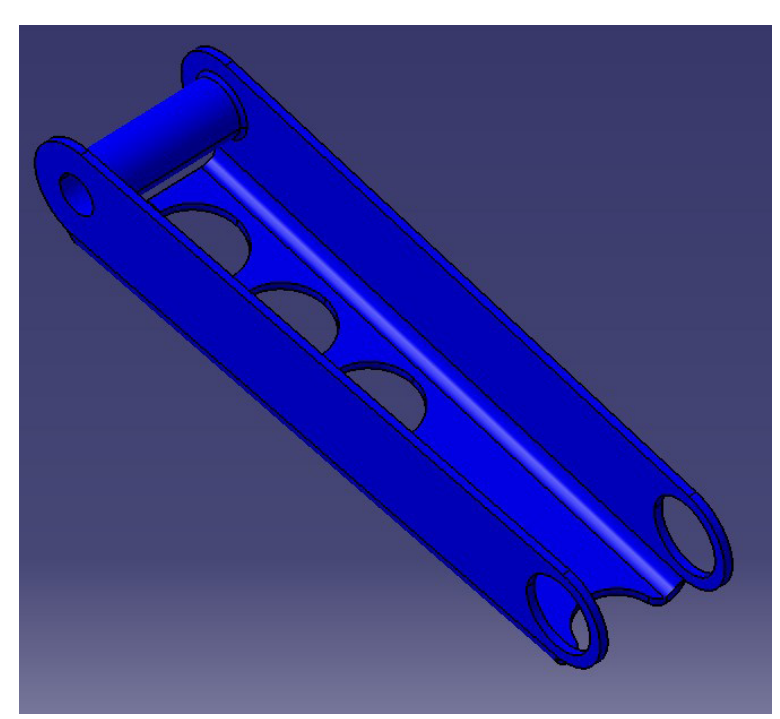

\section{The stresses in the rod of car jacks}

Using known forces in beams, calculated according to equation 2 and 3 , the dimensions of rods and thread spindle can be calculated. Rods have different cross section along their length, so dimensions need to be calculated in the critical cross section. The critical cross section is found on the upper rods where they are connected with shaft. The design of the upper rod and its cross section is shown in Figure 4.

The center of gravity for cross section shown on Figure $4 \mathrm{~b}$ can be calculated using this equation:

$$
\mathrm{y}_{\mathrm{c}}=\frac{\sum \mathrm{A}_{\mathrm{i}} \mathrm{y}_{c \mathrm{i}}}{\Sigma \mathrm{A}_{\mathrm{i}}}=\frac{2\left(A_{1} y_{c 1}+A_{2} y_{c 2}+A_{3} y_{c 4}\right)+A_{4} y_{c 4}}{2\left(A_{1}+A_{2}+A_{3}\right)+A_{4}}
$$

The load force of thecar jack is transmitted from shaft to rods. The center of gravity of rod is not aligned with the center of gravity of shaft; hence, the rod is loaded with pressure which is not aligned with rod axis. Basically, the rod is loaded with combination of pressure and bending.

The pressure stress can be calculated using this equation:

$$
\sigma_{p}=\frac{S_{1}}{A}=\frac{S_{1}}{2\left(A_{1}+A_{2}+A_{3}\right)+A_{4}}
$$

Bending stress, in upper and lower fibers can be calculated using these equations:

$$
\sigma_{s-}=\frac{M_{x}}{I_{x}} y_{c} ; \sigma_{s+}=\sigma_{s-} \frac{h-y_{c}}{y_{c}}
$$

b)

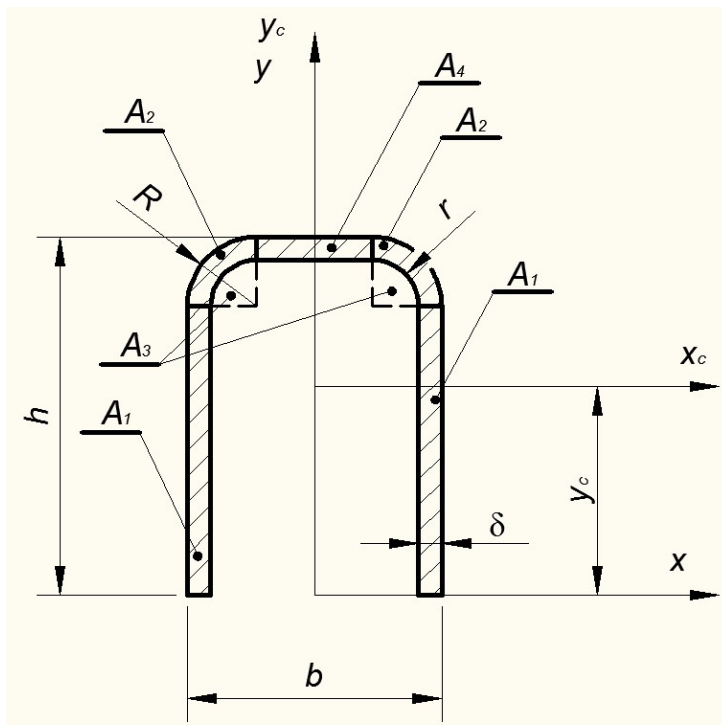

Figure 4. Design of upper rod: a) 3D model, b) cross section 
Maximal stress occurs in lower fibers of the rod, because they are in greater distance from the center of gravity. It can be calculated according to this equation:

$$
\sigma_{\max }=\sigma_{p}+\sigma_{s-}
$$

Minimal stress occurs in upper fiber of the rod. It can be calculated according to this equation:

$$
\sigma_{\min }=\sigma_{p}-\sigma_{s+}
$$

\section{The stresses in the threaded spindle of car jack}

The tread spindle is analyzed only according to tensile stress. It is well-known that tensile stress is equal to ratio of force and cross section area. For the treaded spindle, the cross section area can be calculated approximately as circle where the diameter of circle is the arithmetic mean of diameters $\mathrm{d}_{2}$ and $\mathrm{d}_{3}$ (Figure 5).

The tensile stress in thread spindle is calculated according to the equation:

$$
\sigma_{z}=\frac{F_{V}}{A_{s}}=\frac{F_{V}}{\frac{\left(d_{2}^{2}+d_{3}^{2}\right)}{2} \cdot \frac{\pi}{4}}=\frac{8 F_{V}}{\left(d_{2}^{2}+d_{3}^{2}\right) \pi}
$$

The number of turns of the threaded nut can be calculated using the following equation:

$$
z=\frac{F_{V}}{p_{d} \cdot d_{2} \cdot \pi \cdot H_{1}}
$$

where: $F_{V}$ - load force of threaded spindle,

$d_{2}$ - thread spindle middle diameter,

$d_{3}$ - thread spindle core diameter,

$z$ - number of turns of threaded nut,

$H_{1}$ - depth of basic thread profile,

$p_{d}$ - maximum allowed contact pressure for steel on steel.

\section{STRUCTURAL ANALYSIS OF CAR JACK}

The structural analysis is one of the most common areas of research which use finite element method. FEM is type of analysis where analyzed body is divided by a finite number of small volume elements, which are connected by joints $[6,7,8,9,11,12]$.

The numerical analysis was carried out using FEM in software CATIA V5. The procedure was divided into several steps.

The first step was to define finite elements. In this research, the finite elements were chosen in the form of tetrahedron with parabolic edge. This type of finite element needs to be chosen when there are some curved surfaces on the body, which is exactly the case in this research. This is especially important to successfully simulate the threaded spindle body.

The second step was to define the material for all parts of car jack. For the threaded spindle and threaded nut, steel 8.8 is chosen. For other parts of the car jack, standard construction steel is used, S235 and S275.

The third step of numerical analysis was to define loads and boundary conditions. The car jack has only one load at the top, which represents part of the weight of whole car. According to the available car jacks on the market and production specifications, the maximum load of the car jack is $900 \mathrm{~kg}$. The place of load is shown infigure 6 . The boundary conditions need to be defined because some degrees of freedom for car jack parts must be restricted. Additionally, while using boundary conditions, all connections between parts must be defined.

Defining the boundary conditions always starts with definitions of fixed parts. For the car jack, the fixed part during lifting is the stand (red part on Figure 6) and the fixed surface is

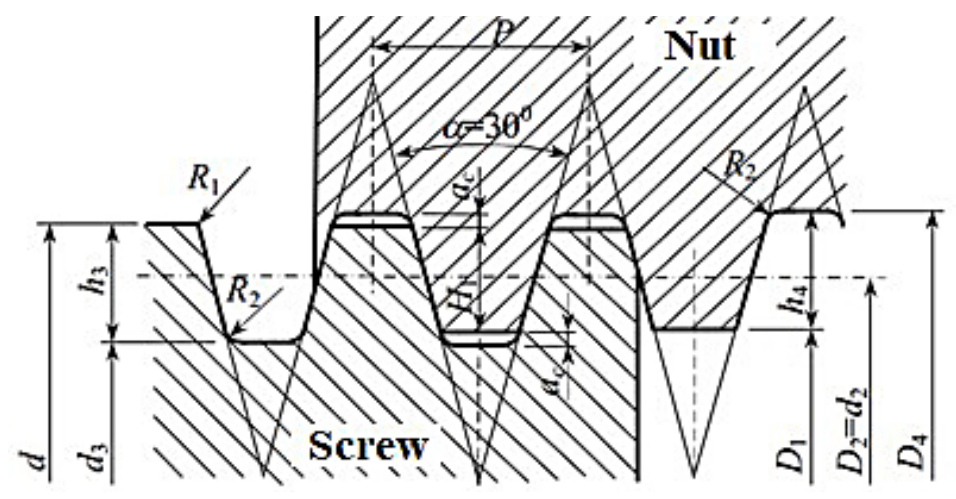

Figure 5. Shape of trapezoidal thread 


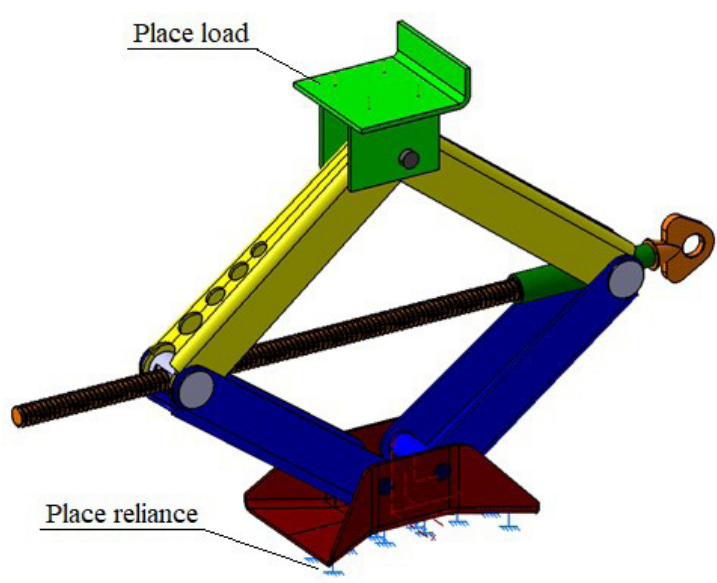

Figure 6. Defined loads and boundary conditions

the bottom surface of stand (place reliance on Figure 6).

After defining all the above-mentioned steps, a solver numerically solved the finite elements equation system taking all defined boundary

a)

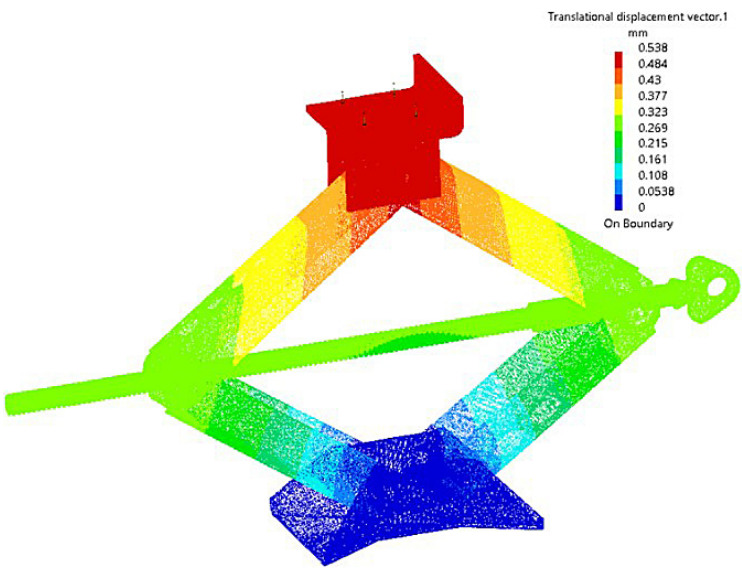

conditions, connections and loads applied on car jack as inputs. After numerical calculation, postprocessing process had to be carried out. The results of FEM were shown by the software $[13,14,15,16,3,4]$.

The most important results for this type of research and analysis are the obtained displacements vectors, Von Mises stress and principals stresses direction and intensity (Figure 7 and 8 ).

\section{RESULTS}

The results of analytical and numerical calculations for upper and lower rods are shown in Table 1. The maximal value of stress is in lower rod (107.7 $\mathrm{MPa}$ ) in upper fibers of the rod. The minimal value of stress is in the same rod but in lower fibers ( 7.75 $\mathrm{MPa}$ ). This is the proof that the rod is loaded with pressure which is not aligned with rod axis.

b)

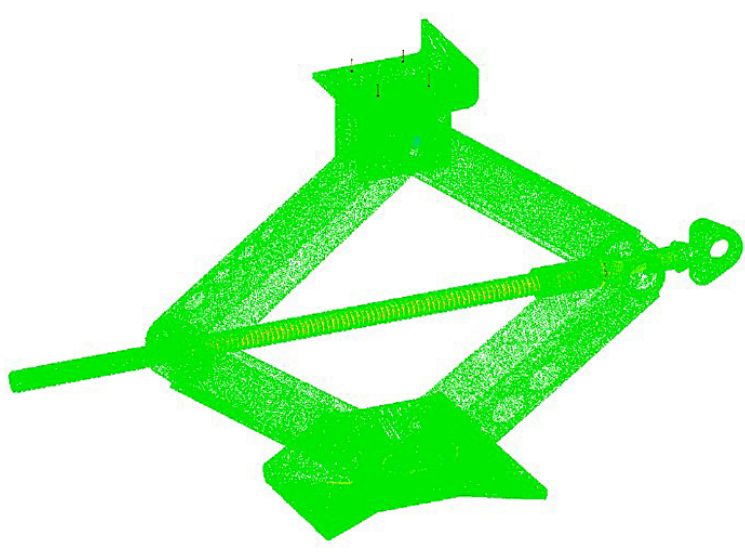

Figure 7. Postprocessing; a) displacements vectors, b) principals stresses

a)

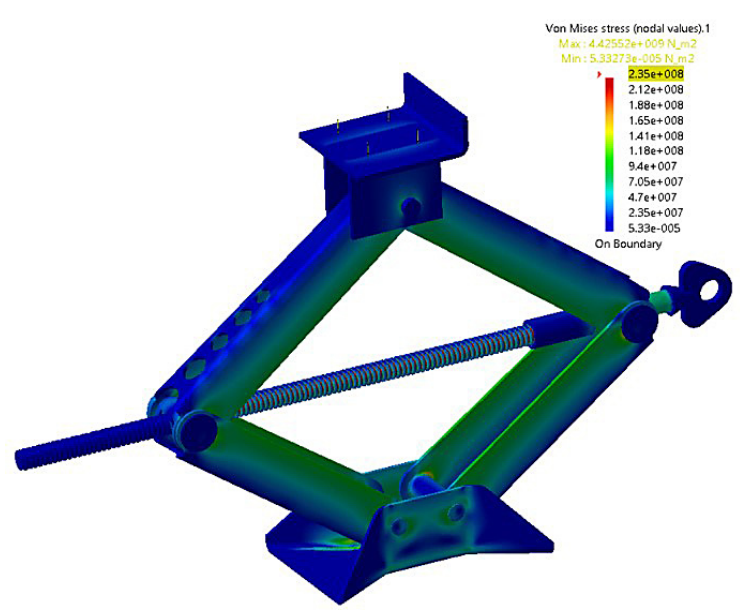

b)

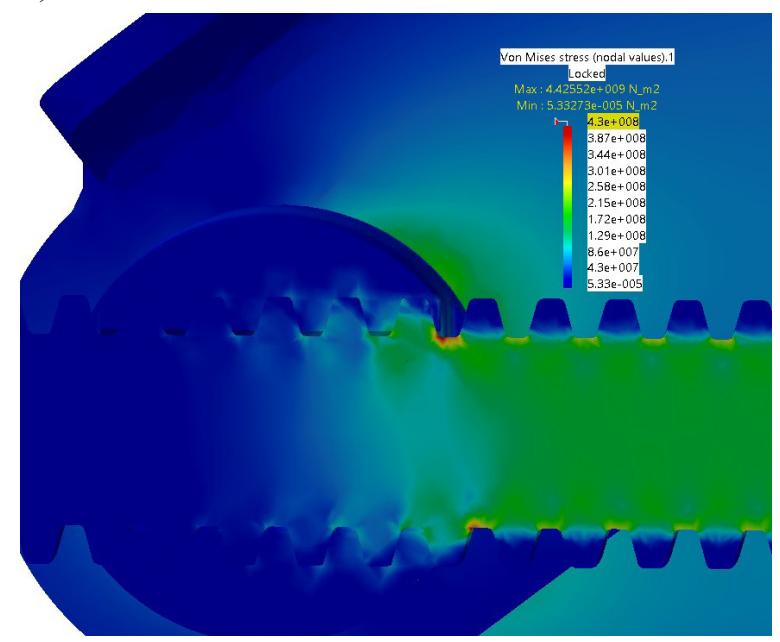

Figure 8. Von Misses stress: a) Full car jack, b) threaded spindle and threaded nut 
Degrees of safety $\mathrm{S}_{\mathrm{m}}$ and $\mathrm{S}_{\mathrm{v}}$ (according to yield stress and according to tensile strength) are greater than 2, which is proof that selected materials are good enough for car jack rods. Table 1 indicates that the error ranges from $2.6 \%$ for minimal value of stress in lower rod, up to $5.2 \%$ also for minimal value of stress, but for upper rod. Taking into consideration the complexity of the numerical analysis, it can be concluded that value of error is satisfactory.

The results of analytical and numerical calculations for the threaded spindle are shown in Table 2. The error is this case is $5.1 \%$ which is satisfactory. Degrees of safety, according to yield stress, are satisfactory for both numerical and analytical calculations for all materials. It can be concluded that this design of car jack will successfully work and deformation will be avoided $\left(\mathrm{S}_{\mathrm{M}}>3\right)$.

The reference degree of safety, according to tensile strength, is from 1.25 up to 2.5 . It can be concluded that according to the analytical calculation, deformation will be avoided because the degree of safety for all materials is greater than the reference values. According to numerical calculation, degrees of safety for materials 1.1172 and 1.1192 are inside references values.
For other three materials they are greater than reference values.

\section{CONCLUSION}

1. The goal of this paper was to develop a parametric CAD model of a car jack. This model was used to carry out numerical structural analysis of the car jack, according to the maximal load specified by the production specification. The materials for all car jack parts were chosen by referencing available literature and production specifications.

2. The created 3D parametric car jack model is a fully functional 3D model with all parameters and relations inside. Thus, conducting the numerical structural analysis was possible for all positions of the car jack during the lifting of a car. The numerical model of car jack includes defined part connection, loads and boundary conditions.

3. The numerical structural analysis was conducted when the car jack was at its lover position (at the beginning of car lifting), because that is the case when the car jack is maximally

Table 1. Results of calculation for car jack rods

\begin{tabular}{|c|c|c|c|c|c|c|c|c|c|c|c|}
\hline \multirow{3}{*}{ Rod } & \multirow{3}{*}{ Material } & \multicolumn{4}{|c|}{ Analytical calculation } & \multicolumn{4}{|c|}{ Numerical calculation } & \multicolumn{2}{|c|}{ Error [\%] } \\
\hline & & $\sigma_{\min }$ & $\sigma_{\max }$ & $S_{m}$ & $S_{v}$ & $\sigma_{\min }$ & $\sigma_{\max }$ & $S_{m}$ & $S_{v}$ & & \\
\hline & & {$[\mathrm{MPa}]$} & {$[\mathrm{MPa}]$} & {$[-]$} & {$[-]$} & {$[\mathrm{MPa}]$} & {$[\mathrm{MPa}]$} & {$[-]$} & {$[-]$} & $\min$ & $\max$ \\
\hline \multirow{2}{*}{ Upper } & S235 & \multirow{2}{*}{14.98} & \multirow{2}{*}{93.31} & $3.8-5.4$ & 2.5 & \multirow{2}{*}{14.20} & \multirow{2}{*}{97.49} & $3.6-5.2$ & 2.4 & \multirow{2}{*}{5.2} & \multirow{2}{*}{4.4} \\
\hline & S275 & & & $4.8-6.2$ & 2.9 & & & $4.6-5.9$ & 2.8 & & \\
\hline \multirow{2}{*}{ Lower } & S235 & \multirow{2}{*}{7.75} & \multirow{2}{*}{107.7} & $3.3-4.7$ & 2.1 & \multirow{2}{*}{7.96} & \multirow{2}{*}{103.7} & $3.4-4.9$ & 2.2 & \multirow{2}{*}{2.6} & \multirow{2}{*}{3.7} \\
\hline & S275 & & & $4.1-5.3$ & 2.5 & & & $4.3-5.5$ & 2.6 & & \\
\hline
\end{tabular}

Table 2. Results of numerical and analytical calculations for threaded spindle

\begin{tabular}{|c|c|c|c|c|c|c|c|}
\hline \multirow{2}{*}{ Material } & \multicolumn{3}{|c|}{ Analytical calculation } & \multicolumn{3}{|c|}{ Numerical calculation } & \multirow{2}{*}{ Error $\sigma[\%]$} \\
\hline & $\sigma[M P a]$ & $S_{m}[-]$ & $S_{v}[-]$ & $\sigma[M P a]$ & $S_{m}[-]$ & $S_{v}[-]$ & \\
\hline 1.1172 & \multirow{5}{*}{164.14} & $3.8-4.7$ & 2.6 & \multirow{5}{*}{172.5} & $3.6-4.5$ & 1.6 & \multirow{5}{*}{5.1} \\
\hline 1.1192 & & $4.2-5.1$ & 2.9 & & $4.0-4.9$ & 1.8 & \\
\hline 1.7033 & & $5.4-6.7$ & 4.2 & & $5.2-6.3$ & 2.5 & \\
\hline 1.7034 & & $5.7-6.7$ & 4.5 & & $5.5-6.3$ & 2.7 & \\
\hline 1.7225 & & $6.7-7.2$ & 5.4 & & $6.3-7.5$ & 3.2 & \\
\hline
\end{tabular}


loaded. Using numerical structural analysis it was proven that the materials chosen for car jack parts meet the required stresses for applied maximal load. The values of all stresses were in the reference range. The numerical structural analysis was performed in CATIA V5 software package.

4. The values of numerically obtained results were validated using analytical calculations for critical places at some parts of car jack. The balues of numerically obtained results deviate from the analytically obtained results in the range from $2.6 \%$ up to $5.2 \%$, which can be considered as great results, taking into consideration the complexity of the car jack design.

5. The main conclusion of this research is that the analyzed car jack design will successfully hold applied loads specified by the manufacturer, with satisfactory safety degrees. Development of this type of parametric 3D model enables easy change of the car jack position during lifting, which is especially suitable for design optimization. Optimization of the car jack design can be subject of future research.

\section{REFERENCES}

1. Budynas, G.R., Nisbett, J.K. Shigley's Mechanical Engineering Design, 8th edition. McGraw-Hill Education, New York, 2008.

2. Chang S.D., Liaw H.S. Motor Driven Scissor Jack forAutomobiles. US Patent Number 4653727, Da Li Hsien, TW, 1987.

3. Delić, M., Čolić, M., Mešić, E. and Pervan, N. Analytical Calculation And FEM Analysis Main Girder Double Girder Bridge Crane. TEM Journal. 6(1), 2017, 48-52.

4. Delić, M., Pervan, N., Čolić, M. and Mešić, E. Theoretical and experimental analysis of the main girder double girder bridge cranes. International Journal of Advanced and Applied Sciences, 6(4), 2019, 75-80.

5. Farmer D.E. Automatic Jack and Wheel Change System. US Patent Number 6237953, Mt. Gay, WV, 2001.

6. Mešić, E., Avdić, V., Pervan, N. and Repčić, N. Finite element analysis and experimental testing of stiffness of the Sarafix external fixator. Procedia Engineering, 100, 2015, 1598-1607.

7. Mešić, E., Pervan, N., Repčić, N. and Muminović, A. Research of influential constructional parameters on the stability of the fixator Sarafix. Annals of DAAAM for 2012 \& Proceedings of the 23rd
International DAAAM Symposium „Intelligent Manufacturing \& Automation: Focus on Sustainability", Editor: Katalinic B., Zadar, Croatia, October 24th-27th, 2012, 561-564.

8. Mešić, E., Avdić, V. and Pervan, N. Numerical and experimental stress analysis of an external fixation system. Folia Medica Facultatis Medicinae Universitatis Saraeviensis, 50(1), 2015, 74-80.

9. Mešić, E., Muminovic, J. A. and Repčić, N. Geometrical modelling and structural analysis of the Sarafix fixator configurations. Annals of DAAAM for 2012 \& Proceedings of the 23rd International DAAAM Symposium „Intelligent Manufacturing \& Automation: Focus on Sustainability", Editor: Katalinic B., Zadar, Croatia, October 24th-27th, 2012, 69-74.

10. Mickael, E. Motor Driven Scissor Jack with Limit Switches. US Patent Number 6695289 B1, 2004.

11. Muminovic, J. A., Saric, I. and Repcic, N. Numerical Analysis of Stress Concentration Factors. Procedia Engineering, 100, 2015, 707-713.

12. Muminovic, J. A., Braut, S., Muminovic, A. and Saric, I. Numerical and analytical analysis of elastic rotor natural frequency. TEM Journal, 3(4), 2014, 323-328.

13. Pervan, N., Mešić, E., Čolić, M. and Avdić, V. Stiffness Analysis of the Sarafix External Fixator based on Stainless Steel and Composite Material. TEM Journal, 4(4), 2015, 366-372.

14. Pervan, N., Mešić, E. and Čolić, M. Stress analysis of external fixator based on stainless steel and composite material. International Journal of Mechanical Engineering \& Technology, 8(1), 2017, 189-199.

15. Pervan, N., Mešić, E., Čolić, M. and Avdić, V. Stiffness analysis of the sarafix external fixator of composite materials. International Journal of Engineering \& Technology, 5(1), 2016, 20-26.

16. Pervan, N., Čolić, M., Šarić, I. and Hadžiabdić, V. Analysis of the Haulage Ropes on Ropeways in Case of Accidental Loads. TEM Journal, 5(2), 2016, 171-174.

17. Pickles J. Portable Powered Screw Jack Actuator Unit. US Patent Number 4749169, Troy, MI, 1988.

18. Saric I., Pervan N., Muminovic A. and Colic, M. Development of Integrated Intelligent Cad System for Design of Shafts. Tehnički vjesnik, 25(Supplement 1), 2018, 99-104.

19. Saric I. and Muminovic A. J. Development of integrated intelligent CAD system for synthesis and stress-deformation analysis of pressure vessels. International Journal of Engineering \& Technology, 7(1), 2018, 147-151.

20. Whittingham R.P. Vehicle Jack. US Patent Number 4969631, Tustin, CA, 1990. 